Jeroen S. Goede $\cdot$ Rudolf Benz $\cdot$ Joerg Fehr •

Klaus Schwarz $\cdot$ Hermann Heimpel

\title{
Congenital dyserythropoietic anemia type I with bone abnormalities, mutations of the CDAN I gene, and significant responsiveness to alpha-interferon therapy
}

Received: 27 April 2006 / Accepted: 3 May 2006 / Published online: 10 June 2006

C) Springer-Verlag 2006

\begin{abstract}
Congenital dyserythropoietic anemia type I (CDA I) is a rare autosomal recessive disorder with ineffective erythropoiesis, characteristic morphological abnormalities of erythroblasts, and iron overloading. CDA I is caused by mutations in the CDAN I gene, encoding a protein named codanin-1. Complex bone abnormalities, especially syndactyly, have not been systematically described with this disease. We present two cases of morphologically and genetically confirmed CDA I with striking bone abnormalities and response to treatment with alpha-interferon. Our cases clearly document the association of skeletal anomalism with CDA I and indicate that codanin-1 may play a role in the development of the skeleton.
\end{abstract}

Keywords CDA I - Dysostosis $\cdot$ Interferon $\cdot$ Skeleton

\section{Introduction}

Congenital dyserythropoietic anemia type I (CDA I, MIM 224120) is a rare autosomal recessive disorder with ineffective erythropoiesis, characteristic morphological

\author{
J. S. Goede $(\bowtie)$ \\ Institute of Oncology and Haematology, City-Hospital Triemli, \\ Birmensdorferstrasse 497, 8063 Zürich, Switzerland \\ e-mail: jeroen.goede@triemli.stzh.ch \\ Tel.: +41-44-4661898 \\ Fax: +41-44-4662747 \\ R. Benz $\cdot$ J. Fehr \\ Clinic of Haematology, University-Hospital Zürich, \\ Zürich, Switzerland
}

K. Schwarz

Department of Transfusion Medicine

University-Hospital Ulm,

Ulm, Germany

H. Heimpel

Department of Internal Medicine III

University-Hospital Ulm,

Ulm, Germany abnormalities of erythroblasts and peripheral red blood cells and iron overloading independent of transfusions [14]. CDA I is caused by mutations in the CDAN I gene encoding codanin-1 [5, 6]. In the German CDA Registry, 103 cases out of 88 families could be identified from published case reports and own unpublished observations. Furthermore, 70 cases in a large Bedouin tribe were described by Tamary et al. from Israel $[7,8]$. Complex bone abnormalities, especially acral dysostosis with syndactyly, have occasionally been described with CDA I [9-14]. The $C D A N$ I gene was sequenced in only a few families with dysostosis, and the relation of dysostosis with the defects in erythropoiesis is not understood. In this paper, we present two cases of morphologically and genetically confirmed CDA I with striking bone abnormalities which share an identical mutation in one but show a different mutation in the other allele of the CDAN I gene. Both patients had a significant response to treatment with alpha-interferon, as shown before in almost all cases reported to receive this type of therapy [4].

\section{Case 1}

The first patient (UPN 178/01 of the German CDA Registry) is a 42-year-old Caucasian male from Switzerland. Two siblings died immediately after birth and one sister as well as both parents are healthy without anemia and without bone malformations. The family was traced back for four generations, all living within one area of Switzerland. The proband presented with congenital anemia first documented at the age of 2 years and with acral dysostosis. Skeletal dysmorphology consisted of mutual syndactyly of the second and third toes with hypoplasia of the fourth metatarsal and unilateral hypoplasia of the distal phalange of the fourth left finger with an aplastic nail (Fig. 1). The malformations of the feet prompted orthopedic corrections shortly after adolescence, resulting in the missing fourth metatarsals and scarred second and third toes (Fig. 1). Besides these skeletal malformations, moderate bilateral ptosis is present since childhood. Our patient grew up with 
chronic anemia disabling him from sportive activity. Anemia occasionally required transfusion therapy in childhood. Because of increasing organomegaly, splenectomy was performed at the age of 9 years, without a significant improvement of anemia. Mental development was normal and the patient graduated as a chemist at the age of 26 years. The diagnosis of CDA I was established after correspondence with H.H. at the end of the 1970s by C. Gasser who presented the two cases of this report at the 6th meeting of the International Society of Hematology in Athens, 1981 [1]. After adolescence, the patient presented stable anemia with hemoglobin concentrations of 8-9 g/dl and a mean corpuscular volume (MCV) of $110-120 \mathrm{fl}$ without need for transfusions. He developed iron overload that has been treated with subcutaneous deferoxamine with fading compliance. Three years ago, the patient was referred to our institution with significant iron overload. According to the widely accepted diagnostic criteria [2], the diagnosis of CDA I was confirmed and we started chelation with deferoxamine and deferiprone. Further analysis showed a compound heterozygous mutation of the CDAN I gene with mutations in exon 24 [3259 insertion (ins) $\mathrm{T}$ ], leading to a frameshift (fs) at the protein level and 26 (C3503T, Pro1129Leu) [3]. Treatment with interferon- $\alpha-2 b$ ( $3 \times 3$ Mio IE per week) resulted in a significant increase of hemoglobin. Tolerance of interferon was good and quality of life improved extensively. As main side effect, transitory asymptomatic neutropenia (minimal $500 / \mu \mathrm{l})$ developed. After 6 months of therapy, we switched to Peginterferon- $\alpha-2 b$. Tolerance was comparable to the non-pegylated form of interferon. We again observed asymptomatic neutropenia.

\section{Case 2}

The second patient (UPN 177/01 of the German CDA Registry) is a 48-year-old Caucasian female from Switzerland. One brother and both parents are not anemic and show no skeletal malformations. The family was traced back for two generations. Besides inborn anemia, the proband has mutual malformations of her toes (Fig. 1) and moderate bilateral ptosis like the first case. After birth and during infancy, she received multiple transfusions. At the age of 9 years, splenectomy and, 6 years later, syndactyly correction of the third and fourth toes on the right foot were performed. After splenectomy, the transfusion interval was reduced, and after adolescence there was no need for further transfusions. Because of increasing ferritin levels, a liver biopsy was carried out at the age of 38, which showed massive siderosis and beginning cirrhosis. An iron chelating therapy was started with deferiprone and was proved to be successful in a second biopsy 3 years later with almost complete normalization of the former findings.
Fig. 1 Pictures of dysostosis in CDA I. a X-ray photograph of the feet of case 1 . b Feet of case 1. c Hypoplasia of the distal phalange of the fourth finger at the left with nail hypoplasia of case 1. d Right and left foot of case 2
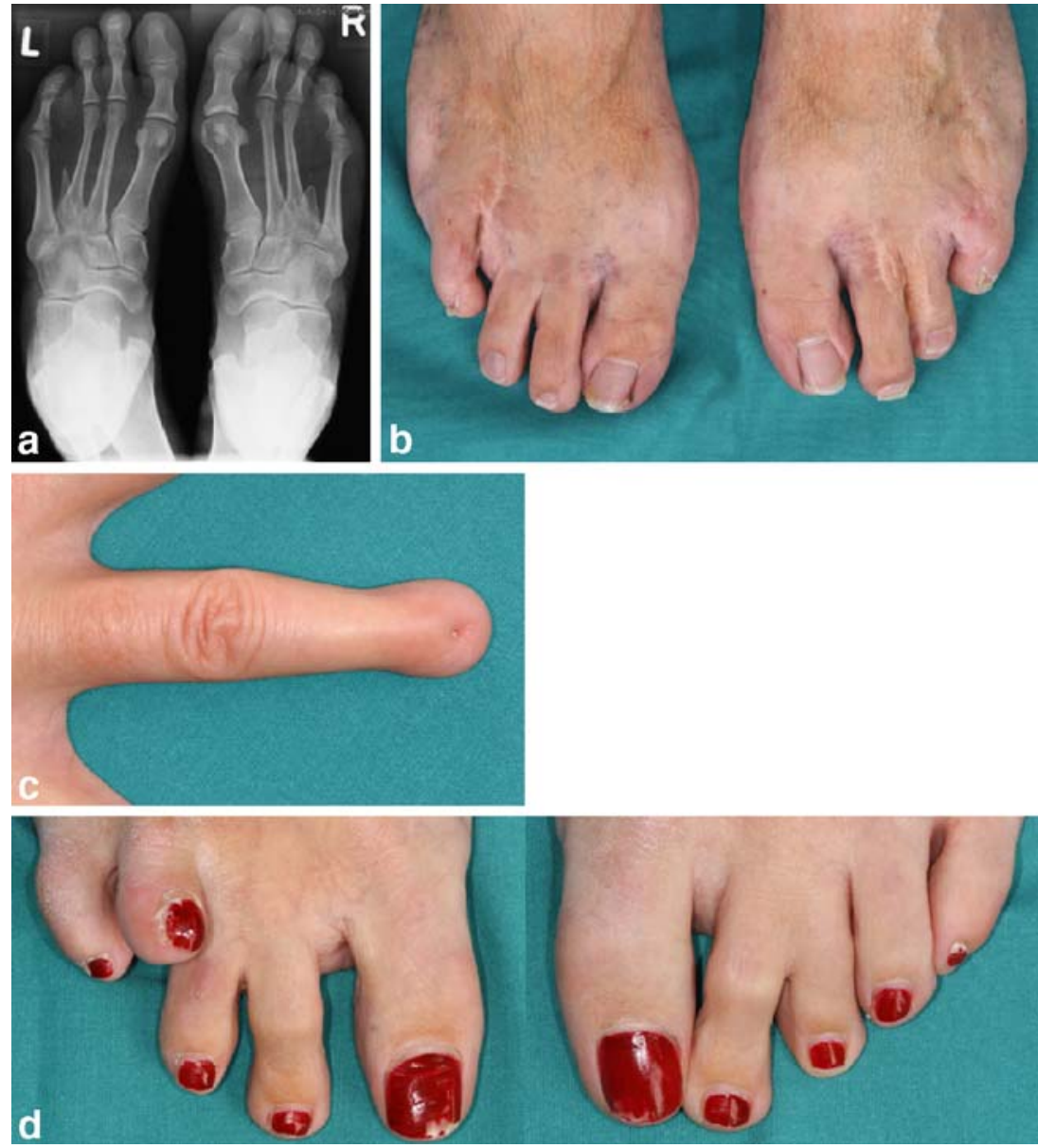
Ferritin levels decreased to normal values and remained in the normal range on continued therapy of very low dose of deferiprone $(500-1,000 \mathrm{mg} / \mathrm{d})$. Hemoglobin levels were stable during the last 10 years with concentrations of 9$10 \mathrm{~g} / \mathrm{dl}$ and a MCV of $100-120 \mathrm{fl}$. The patient suffered from unspecific fatigue most probably related to moderate anemia. A molecular analysis demonstrated a compound heterozygous mutation of the CDAN I gene with affection of exons 12 (A1910G, N598>S) and 24 [3259 ins T; fs] [3]. The parents of the mother, who shares the mutation on exon 24 with the proband, stem from the same region as the parents of the mother of case 1, who also shows the mutation on exon 24. The father originated from England. We started a treatment with interferon- $\alpha-2 b$ with the intention to increase the hemoglobin concentrations and, in the long term, to maintain normal ferritin levels without chelation. Because of marked neutropenia after the initial five doses $(3 \times 3$ Mio units per week), we decreased the dose of interferon to 2 Mio units per week. Since starting the treatment, the hemoglobin levels are between 11 and $12 \mathrm{~g} / \mathrm{dl}$ and the patient feels markedly more vital.

\section{Discussion}

The diagnosis of CDA I is based on the general diagnostic criteria of the CDAs and characteristic abnormalities of erythroblasts seen in light and electron microscopy $[2,3$, $13,15]$. Most patients have a life-long moderate macrocytic anemia which is more severe in infancy and childhood, requiring blood transfusions in this period but not thereafter. Mutations of the CDAN I gene were more recently detected in all members of the Bedouin tribes as observed by scientists from Israel and in 22 out of 24 unrelated European families [3, 6, 16]. Although electron microscopy was not done in the two patients described in this report, they unequivocally fulfill the criteria of CDA I, including mutations in the two alleles of the CDAN I gene. The response to therapy with interferon- $\alpha$ is further support of correct diagnosis.

Morphologic body abnormalities are observed in approximately $10 \%$ of CDA I cases [13] and may be the presenting features for the referral of children [12] to specialized institutions. Among them, dysostosis is partic-
Fig. 2 Hemoglobin concentration and neutrophil count after the beginning of interferon treatment in case 1 (above) and 2
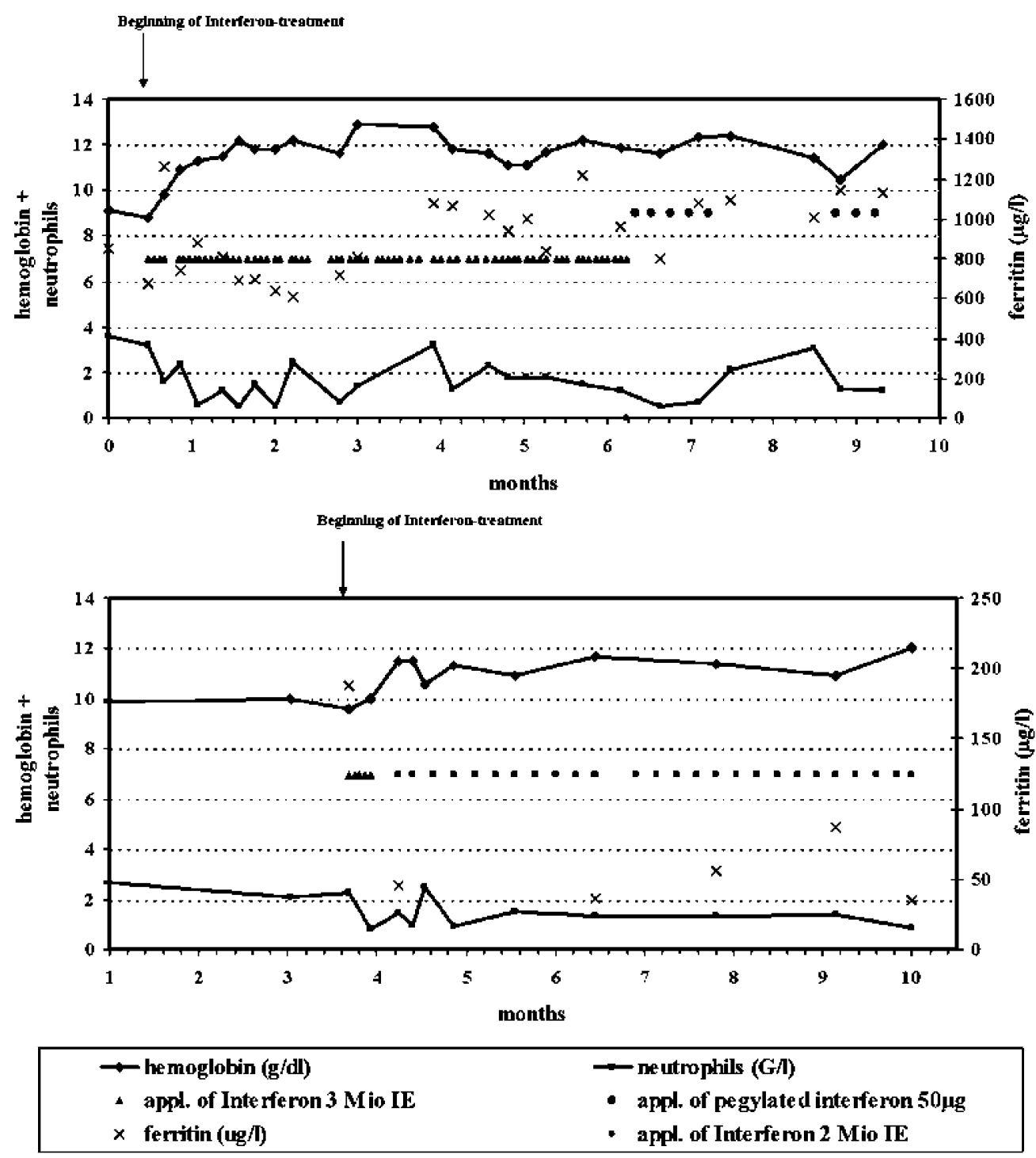
Table 1 Mutations in cases of CDA I with acral dysostosis

\begin{tabular}{lllllllll}
\hline Reference no. & Case no. & Right hand & Left hand & Right foot & Left foot & Exon & Mutation a & Mutation b \\
\hline 3 & $177 / 01$ & $\times$ & $\times$ & $3,4,5$ & $3,4,5$ & 12,24 & Asn598Ser & ins, fs \\
3 & $178 / 01$ & $\times$ & 4 & $2,3,4$ & $2,3,4$ & 24,26 & ins, fs & Pro1129Leu \\
3 & $447 / 01$ & $\times$ & $\times$ & 4 & $\times$ & 26,26 & Pro1129Leu & Pro1129Leu \\
14 & II & $\times$ & $\times$ & $1,4,5$ & $\times$ & 26,26 & Pro1129Leu & Pro1129Leu \\
6 & II & $1,2,3,4,5$ & $1,2,3,4,5$ & $2,3,4,5$ & $2,3,4,5$ & 12,12 & IVS12+5G $>$ A & IVS12+5G $>$ A \\
6 & III & 3,4 & $\times$ & 4,5 & $2,3,4,5$ & 14,14 & Pro671Leu & Arg687Trp \\
6 & V & $\times$ & $\times$ & $\times$ & 4,5 & 8,14 & IVS8+1G $>$ A & Pro671Leu \\
\hline
\end{tabular}

Numbers indicate the fingers or toes with osseous dysmorphology. Amino acid assignment is according to NP 612486 ins Insertion, $f s$ frameshift

ularly frequent, consisting of foot and hand dysmorphologies as were seen in our patients (Fig. 1). The observation that the two patients described show similar dysostosis of both feet and that the patients share an identical exon 24 mutation of CDAN I allowed the hypothesis that either this specific allele of CDAN I or a variation in a gene linked to this allele at chromosome $15 \mathrm{q} 15$ may act dominantly and be causative for the dysmorphologies. This hypothesis was dismissed on the fact that the ancestors of both probands, being heterozygotes for these mutations and coming from the same region in Switzerland (and may therefore be related, although this was not proven by pedigree data available), were unaffected. In addition, as shown in Table 1, similar patterns of dysostosis were observed in unrelated families showing other CDAN I mutations, excluding the specificity of the exon 24 mutation for skeletal dysmorphologies.

In drosophila, the cytoplasmic codanin-1-like protein discs lost (dlt) is needed for cell survival and cell cycle progression. In the absence of dlt, the $\mathrm{S}$ phase of the cell cycle cannot be completed and, thus, mitosis cannot be initiated. A lack of dlt leads to a $30 \%$ reduction in the number of blood cells in third instar larvae and to a variable loss of imaginal discs [17]. These observations in drosophila hint at the possibility that codanin-1 may be involved in several developmental pathways, explaining the human phenotype of dyserythropoietic anemia and dysostosis in some cases.

The favorable response to interferon- $\alpha$ in the two patients observed (Fig. 2) confirms similar data on patients with CDA I, with the exception of three unrelated cases from India [18]. There is not only an improvement of the hemoglobin level but, in a long-term perspective, a reduction of iron overload that can also be achieved [19]. As side effects of interferon can reduce the compliance and may result in neutropenia, dose adjustments are required. Our data, so far, confirm a decreased need for chelation therapy among patients on an interferon regimen.

\section{References}

1. Delaunay J, Iolascon A (1999) The congenital dyserythropoietic anemias. Bailliere's Best Pract Res Clin Haematol 12 (4):691-705
2. Heimpel H (2004) Congenital dyserythropoietic anemias: epidemiology, clinical significance and progress in understanding their pathogenesis. Ann Hematol 83(9):613-621

3. Heimpel H, Schwarz K, Ebnöther M, Goede JS, Heydrich D, Kamp T, Lothar P, Rath B, Roessler J, Schildknecht O, Schmid M, Wuillemin W, Einsiedler B, Leichtle R, Tamary H, Kohne E (2006) Congenital dyserythropoietic anemia type I (CDA I): molecular genetics, clinical appearance and prognosis based on long-term observation. Blood 107(1):334-340

4. Wickramasinghe SN, Wood WG (2005) Advances in the understanding of the congenital dyserythropoietic anemias. Br J Haematol 131(4):431-446

5. Dgany O, Avidan N, Delaunay J, Krasnov T, Shalmon L, Shalev H, Eidelitz-Markus T, Kapelushnik J, Cattan D, Pariente A, Tulliez M, Cretien A, Schischmanoff PO, Iolascon A, Fibach E, Koren A, Rossler J, Le Merrer M, Yaniv I, Zaizov R, Ben-Asher E, Olender T, Lancet D, Beckmann JS, Tamary H (2002) Congenital dyserythropoietic anemia type I is caused by mutations in codanin-1. Am J Hum Genet 71(6):1467-1474

6. Tamary H, Dgany O, Proust A, Krasnov T, Avidan N, EidelitzMarkus T, Tchernia G, Genevieve D, Cormier-Daire V, BaderMeunier B, Ferrer-Vacher C, Munzer M, Gruppo R, Fibach E, Konen O, Yanif I, Delaunay J (2005) Clinical and molecular variability in congenital dyserythropoietic anemia type I. Br J Haematol 130(4):628-634

7. Tamary H, Shalmon L, Shalev H, Shaft D, Zoldan M, Resnitzky P, Korostishevky M, Zaizov R (1996) Localisation of the gene for congenital dyserythropoietic anemia type I to chromosome 15q15.1.3. Blood 88(Suppl 1):144

8. Shalev H, Kapelushnik J, Moser A, Dgany O, Krasnov T, Tamary H (2004) A comprehensive study of the neonatal manifestations of congenital dyserythropoietic anemia type I. J Pediatr Hematol Oncol 26(11):746-748

9. Holmberg L, Jansson L, Rausing A, Henriksson P (1978) Type I congenital dyserythropoietic anemia with myelopoietic abnormalities and hand malformations. Scand J Haematol 21:72-79

10. Brichard B, Vermylen C, Scheiff JM, Michaux JL, Ninane J, Cornu G (1994) Two cases of congenital dyserythropoietic anemia type I associated with unusual skeletal abnormalities of the limbs. Br J Haematol 86:201-202

11. Le Merrer M, Girot R, Parent P, Cormier Daire V, Maroteaux P (1995) Acral dysostosis dyserythropoiesis syndrome. Eur J Pediatr 154:384-388

12. Sabry MA, Zaki M, al Awadi SA, al Saleh Q, Mattar MS (1997) Non-haematological traits associated with congenital dyserythropoietic anemia type 1: a new entity emerging. Clin Dysmorph 6(3):205-212

13. Wickramasinghe SN (1998) Congenital dyserythropoietic anemias: clinical features, haematological morphology and new biochemical data. Blood Rev 12:178-200 
14. Roda L, Pasche J, Fournier A, Terorotua V, Wickramasinghe SN, Tamary H, Schischmanoff PO, Tchernia G, Delaunay J (2002) Congenital dyserythropoietic anemia, type 1, in a Polynesian patient: response to interferon alpha2b. J Pediatr Hematol Oncol 24(6):503-506

15. Delaunay J (2003) Red cell membrane and erythropoiesis genetic defects. Hematol J 4(4):225-232

16. Tamary H, Dgany O, Proust A, Krasnov T, Avidan N, Tschernia G, Genevieve D, Comier-Darre V, Le Merrer M, BaderMeunier B, Ferrero-Vacher C, Yaniv, I, Delaunay J (2004) Molecular basis of congenital dyserythropoietic anemia type I in French patients. Blood 104(11):13b
17. Pielage J, Stork T, Bunse I, Klambt C (2003) The Drosophila cell survival gene discs lost encodes a cytoplasmic codanin-1like protein, not a homolog of tight junction PDZ protein Patj. Dev Cell 5(6):841-851

18. Marwaha RK, Bansal D, Trehan A, Garewal G (2005) Interferon therapy in congenital dyserythropoietic anemia type I/II. Pediatr Hematol Oncol 22(2):133-138

19. Lavabre-Bertrand T, Ramos J, Delfour C, Henry L, Guiraud I, Carillo S, Wagner A, Bureau JP, Blanc P (2004) Long-term alpha interferon treatment is effective on anemia and significantly reduces iron overload in congenital dyserythropoiesis type I. Eur J Haematol 73(5):380-383 